\title{
Significances and Outcomes of Mechanical Thrombectomy for Acute Infarction in Very Elderly Patients : A Single Center Experience
}

\author{
Dong Hun Kim, M.D., Sang Uk Kim, M.D., ${ }^{2}$ Jae Hoon Sung, M.D., ${ }^{1}$ Dong Hoon Lee, M.D., ${ }^{1}$ Ho Jun Yi, M.D., ${ }^{1}$ Sang Won Lee, M.D. \\ Department of Neurosurgery, St. Vincent's Hospital, College of Medicine, The Catholic University of Korea, Suwon, Korea \\ Department of Neurosurgery, ${ }^{2}$ Daejeon St. Mary's Hospital, College of Medicine, The Catholic University of Korea, Daejeon, Korea
}

Objective : Mechanical thrombectomy is increasingly being used for the treatment of acute ischemic stroke. The population over 80 years of age is growing, and many of these patients have acute infarction; however, these patients are often excluded from clinical trials, so the aim of this study was to compare the functional outcomes and complication rates in very elderly patients (age $\geq 80$ years) and aged patients (60-79 years) treated with mechanical thrombectomy.

Methods : Between January 2010 and June 2015, we retrospectively reviewed 113 senior patients (over 60 years old) treated at our institution for acute ischemic stroke with mechanical thrombectomy. They were divided into a very elderly ( $\geq 80$ years) and aged (60-79 years) group, with comparisons in recanalization rates, complications, death and disability on discharge be reported.

Results : The mean age was 70.3 years in the aged group and 83.4 years in the very elderly group. Elderly patients had higher rates of mechanical thrombectomy failure than the younger group ( $40 \%$ vs. $14 \%$; odds ratio [OR] 4.1; $95 \%$ confidence interval [Cl] 1.4-11.9; $p=0.012$ ). Results from thrombolysis in cerebral ischemia and modified Rankin scale at discharge were worse in the older group ( $p=0.005$ and 0.023 respectively). There were no differences in mortality rate or other complications, but infarction progression rates were significantly higher in the very elderly group. (15\% vs. $2.2 \%$; OR $8.0 ; 95 \% \mathrm{Cl} 1.2-51.7 ; p=0.038$ ). The majority (92.3\%) of the patients who failed in aged group were not successful after several trials. However, in half (4 of 8$)$ of the very elderly group, the occlusion site could not be accessed.

Conclusion : Patients older than 80 years of age undergoing mechanical thrombectomy for acute infarction were more difficult to recanalize due to inaccessible occlusion sites and had a higher rate of infarction progression, However, mortality and other complications were similar to those in younger patients.

Key Words : Infarction · Aged · Thrombectomy · Aged, 80 and over.

- Received : December 23, 2016 •Revised : January 31, 2017 •Accepted : September 30, 2017

- Address for reprints : Sang Uk Kim, M.D.

Department of Neurosurgery, Daejeon St. Mary's Hospital, College of Medicine, The Catholic University of Korea, 64 Daeheung-ro, Jung-gu, Daejeon 34943, Korea Tel : +82-42-220-9114, Fax : +82-42-222-6601, E-mail : tkddnr79@hanmail.net

This is an Open Access article distributed under the terms of the Creative Commons Attribution Non-Commercial License (http://creativecommons.org/licenses/by-nc/4.0) which permits unrestricted non-commercial use, distribution, and reproduction in any medium, provided the original work is properly cited. 


\section{INTRODUCTION}

Although mortality rates have decreased, cerebrovascular disease, including stroke, are still a major cause of death, especially in the elderly in Korea ${ }^{24)}$. Mechanical thrombectomy is being used commonly for the treatment of acute ischemic stroke, and recent clinical guidelines recommended endovascular recanalization therapy ${ }^{10)}$. After the publication of five clinical trials ${ }^{2,3,7,11,21)}$, this procedure has been considered the standard treatment for anterior circulation occlusion patients $^{20)}$, with reported benefits in most patients with acute ischemic stroke, regardless of patient' age, initial stroke severity, and administration of intravenous alteplase ${ }^{8)}$.

Some studies have investigated treatment with conventional intravenous thrombolysis in the elderly ${ }^{17,22)}$, however, patients over 80 years of age were mostly excluded from trials, and no large-scale studies distinctly investigated age-specific outcomes of mechanical thrombectomy $y^{4}$. The aging population is more susceptible to decreased neuronal plasticity, considerably due to a lack of neurologic restoration, therefore, older infarction patients have poorer overall outcomes ${ }^{5}$.

In this study, we compared the functional outcomes and complication rates in very elderly patients (age $\geq 80$ years) versus aged patients (60-79 years) in a single center after treatment with mechanical thrombectomy.

\section{MATERIALS AND METHODS}

This study was approved by the Institutional Review Board and we retrospectively reviewed 113 senior patients (over 60 years old) who were treated for acute ischemic stroke with mechanical thrombectomy at our institution between January 2010 and June 2015. The patients were divided into two subgroups : those between 60 and 79 years old and those 80 years of age or over. Variables were compared between these subgroups.

The institutional management criteria for acute ischemic stroke are : 1) imaging evaluation performed immediately after visiting the emergency room (ER) and identifying the presence of hemorrhage, cerebral artery occlusion sites, and perfusion defects with perfusion computed tomography (CT); 2) administration of $0.9 \mathrm{mg} / \mathrm{kg}$ (10\% bolus and $90 \%$ continuous infusion during 1 hour) if eligible for intravenous tissue plasminogen activator (tPA); 3) infarction area verified with magnetic resonance (MR) diffusion weighted imaging and the decision to treat with thrombectomy made by the neurosurgeons and neuro-interventionists considering the perfusion diffusion mismatching; 4) under informed consent from patients or their families, endovascular thrombectomy was carried out regardless of age; and 5) after the procedure, all patients underwent non-contrast CT immediately followed by imaging studies such as non-contrast CT and CT or MR angiography.

Patient data were collected including demographic data (sex and age), infarction risk factors, vascular occlusion sites, the use of intravenous tPA, time from symptom onset to ER visit, procedure time, complications (hemorrhage, progression, brain edema, and mortality) and need for secondary operation. Initial severity was assessed by the National Institutes of Health Stroke Scale (NIHSS). Reperfusion was classified using the modified thrombolysis in cerebral infarction (TICI) scale. Functional outcomes at discharge were measured according to the modified Rankin Scale (mRS). Mechanical thrombectomy was defined as the intra-arterial procedure including stent-retriever systems, the Penumbra system (Penumbra Inc., Alameda, CA, USA), and microwire maceration, with or without the administration of a chemical thrombolytic agent (urokinase or tirofiban), complications were classificated as hemorrhage, infarction progression, and brain edema according to the new lesions in the post-procedural imaging study compared with the initial examination, as well as aggravated neurologic symptoms.

The causes of failure were classified into three categories: first, the procedure was considered unsuccessful if occlusion sites were accessible, but recanalization failed after several attempts. Second, if there was no avenue to the occlusion site, the lesion was classified as inaccessible. Finally, guiding failure' was referred to when the guiding system was unable to perform the procedure, despite approaching the lesion.

Statistical analysis was performed using SPSS version 18.0 (IBM Corp., Armonk, NY, USA), continuous variables are presented as means plus or minus standard deviations, and variables were compared between the two subgroups using the Wilcoxon rank sum test for continuous variables and the chisquare or Fisher exact test for categorical variables. Univariate logistic regression models were used for the calculation of the odds ratio and their $95 \%$ confidence intervals. A probability value $<0.05$ was considered statistically significant. 


\section{RESULTS}

A total of 171 patients were treated with endovascular thrombectomy for acute ischemic stroke in our institution between January 1, 2010 and June 30, 2015. Among these patients, 113 were senior patients, over 60 years of age, who underwent mechanical thrombectomy. Within this group of patients, 20 (17.7\%) were very elderly (age $\geq 80$ years) and 93 $(82.3 \%)$ were aged patients (60-79 years). The mean age of the very elderly group was $83.4 \pm 2.3$ years (range, $80-87$ years), and that of the aged group was $70.3 \pm 5.5$ years (range, 60-79 years). Baseline characteristics for the two groups are presented in Table 1.

Fifty-five patients (48.7\%) were male. In older patients, most of whom were female, the percentage of male patients $(20 \%)$ was significantly lower compared to younger patients $(54.8 \%$, $p=0.005)$. There were no significant differences between the two subgroups in the presence of risk factors (hypertension, diabetes mellitus, dyslipidemia, arterial fibrillation, previous stroke, coronary artery disease, malignancy, and renal disease) or time from onset to ER visit and procedure duration. Most occlusions were identified at the internal cerebral artery in both subgroups (54.8\% and 75\% respectively).

The data in Table 2 shows rates of recanalization, clinical outcomes, and complications between the two groups. The NIHSS was administered when patients were initially presented to the ER, and the results were not significantly different between the two groups ( $13.9 \pm 6.4$ vs. $15.6 \pm 6.7 ; p=0.331$ ). However, very elderly patients were four times more likely to have failed recanalization $(8 / 20[40 \%]$ vs. $13 / 93$ [14\%]; $p=0.010)$ and less likely to achieve major reperfusion (TICI score $2 \mathrm{~B}$ and 3 ) than the younger group ( $75.2 \%$ vs. $40 \%$; $p=0.003$ ) (Table 3 ).

Treatment outcome was evaluated at discharge using the mRS. There was a trend toward worse outcomes in the older group, with poor outcomes (mRS score $5-6$ ) in $65 \%$ of very elderly patients versus $37.6 \%$ in aged patients $(p=0.023)$ (Fig. 1, Table 2).

There were no significant differences in the rate of any com-

Table 1. Baseline characteristics of senior patients undergoing mechanical thrombectomy for acute infarction

\begin{tabular}{|c|c|c|c|c|}
\hline & $\begin{array}{c}\text { Total } \\
(n=113)\end{array}$ & $\begin{array}{c}\text { Aged patient } \\
(60-79 \text { years })(n=93)\end{array}$ & $\begin{array}{l}\text { Very elderly patients } \\
\text { (age } \geq 80 \text { years) } \\
(n=20)\end{array}$ & $p$-value \\
\hline Age (years) & $72.6 \pm 7.2$ & $70.3 \pm 5.5$ & $83.4 \pm 2.3$ & $<0.001$ \\
\hline Male sex & $55(48.7)$ & $51(54.8)$ & $4(20.0)$ & 0.005 \\
\hline Hypertension & $73(64.6)$ & $61(65.6)$ & $12(60.0)$ & 0.635 \\
\hline Diabetes mellitus & $30(26.5)$ & $28(30.1)$ & $2(10.0)$ & 0.065 \\
\hline Dyslipidemia & $9(8.0)$ & $8(8.6)$ & $1(5.0)$ & $>0.999$ \\
\hline Arterial fibrillation & $59(52.2)$ & $48(51.6)$ & $1(55.0)$ & 0.783 \\
\hline Previous stroke & $10(8.8)$ & $9(9.7)$ & $1(5.0)$ & 0.688 \\
\hline$C A D$ & $8(7.1)$ & $6(6.5)$ & $2(10.0)$ & 0.630 \\
\hline Malignancy & $5(4.4)$ & $5(5.4)$ & $0(0.0)$ & 0.584 \\
\hline Renal disease & $3(2.7)$ & $2(2.2)$ & $1(5.0)$ & 0.446 \\
\hline Occlusion site & & & & 0.334 \\
\hline ICA & $66(58.4)$ & $51(54.8)$ & $15(75.0)$ & \\
\hline MCA & $27(23.9)$ & $25(26.9)$ & $2(10.0)$ & \\
\hline ACA & $2(1.8)$ & $2(2.2)$ & $0(0.0)$ & \\
\hline BA & $18(15.9)$ & $15(16.1)$ & $3(15.0)$ & \\
\hline IV tPA & $47(41.6)$ & $44(47.3)$ & $3(15.0)$ & 0.008 \\
\hline Time from onset to visit ER (min) & $149.9 \pm 191.1$ & $144.0 \pm 18.0$ & $177.3 \pm 58.5$ & 0.845 \\
\hline Procedure time (min) & $123.4 \pm 62.6$ & $123.8 \pm 6.5$ & $121.7 \pm 14.0$ & 0.979 \\
\hline
\end{tabular}

Values are presented as mean \pm standard deviation or number (\%). CAD : coronary artery disease, ICA : internal carotid artery, MCA : middle cerebral artery, ACA : anterior cerebral artery, BA : basilar artery, ER : emergency room, IV tPA : intravenous tissue plasminogen activator 
Outcome of Mechanical Thrombectomy in Very Elderly Patients | Kim DH, et al.

Table 2. Comparison of recanalization, clinical outcomes and complications between aged patients and very elderly patients

\begin{tabular}{|c|c|c|c|c|}
\hline & Total $(n=113)$ & $\begin{array}{c}\text { Aged patient } \\
(60-79 \text { years }) \\
(n=93)\end{array}$ & $\begin{array}{l}\text { Very elderly patients } \\
\text { (age } \geq 80 \text { years) } \\
(n=20)\end{array}$ & $p$-value \\
\hline Admission NIHSS & $14.2 \pm 6.5$ & $13.9 \pm 6.4$ & $15.6 \pm 6.7$ & 0.331 \\
\hline Reperfusion (TICI) & & & & 0.005 \\
\hline Fail (0) & 21 (18.6) & $13(14.0)$ & $8(40.0)$ & \\
\hline Partial (1-2A) & $14(12.4)$ & $10(10.8)$ & $4(20.0)$ & \\
\hline Major (2B-3) & $78(69.0)$ & $70(75.2)$ & $8(40.0)$ & \\
\hline Outcome (mRS) & & & & 0.023 \\
\hline Good (0-2) & 21 (18.6) & $21(22.6)$ & $0(0.0)$ & \\
\hline Fair (3-4) & $44(38.9)$ & 37 (39.8) & $7(35.0)$ & \\
\hline Poor (5-6) & $48(42.5)$ & $35(37.6)$ & $13(65.0)$ & \\
\hline \multicolumn{5}{|l|}{ Complication } \\
\hline Hemorrhage & 15 (13.3) & $14(15.1)$ & $1(5.0)$ & 0.465 \\
\hline Progression & $5(4.4)$ & $2(2.2)$ & $3(15.0)$ & 0.038 \\
\hline Edema & $6(5.3)$ & $6(6.5)$ & $0(0.0)$ & 0.589 \\
\hline Mortality & $20(17.7)$ & $16(17.2)$ & $4(20.0)$ & 0.752 \\
\hline Operation & $10(8.8)$ & $10(10.8)$ & $0(0.0)$ & 0.205 \\
\hline
\end{tabular}

Values are presented as mean \pm standard deviation or number (\%). NIHSS : National institutes of health stroke scales, $\mathrm{TICl}$ : thrombolysis in cerebral ischemia, mRS : modified Rankin scale

plication, such as hemorrhage, edema, mortality, or re-operation in the posttreatment period. However, infarction progression was observed eight times more often in the very elderly group than the aged group (3/20 [15\%] vs. 2/93 [2.2\%]; $p=0.038)$ (Table 2).

\section{DISCUSSION}

In this study, several infarction risk factors and occlusion vascular sites were identified, using intravenous tPA, time from symptom onset to ER visit, and procedure time. These results showed a few relevant factors, including male sex and tPA, that differed according to the age-related group. Korean statistics showed that the male to female ratio was 0.68 (2197606 men to 3227031 women) in those over 65 years of age, however this ratio decreased to 0.41 (280744 men to 681374 women) in the elderly group, based on the 2010 population and housing census ${ }^{24)}$. It was also reported that the life expectancy of men and women was 79 and 85.5 years, respectively. With increasing age, the size of the male population generally declined, so our study could not avoid a lower per- centage of men in very elderly patients. In addition, the Korean Ministry of Food and Drug safety suggested that using tPA in patients over 80 years of age is contraindicated ${ }^{23)}$. This would result in only a few cases of IV tPA in the very elderly group, however Mazighi et al. ${ }^{16)}$ reported that intravenous and intra-arterial combined treatment in octogenarians had a higher recanalization rate and increased neurological improvement.

Research from Loh et al. ${ }^{14)}$ presented the outcomes of mechanical thrombectomy in patients younger than 80 years of age, but did not state the success rate of recanalization. In another study that analyzed intra-arterial therapy in elderly stroke patients, the authors reported that there were no significant differences in the TICI 2-3 reperfusion rates between those younger than 80 years and 80 years or older $(75.4 \%$ vs. $71.4 \%$; $p=0.57)$. Still, the major reperfusion rate of TICI $2 \mathrm{~B}$ to 3 was lower in very elderly patients $(40 \% \text { vs. } 25 \% ; p=0.06)^{4)}$. We analyzed the success rate of mechanical thrombectomy as TICI 2A or more between aged patients (60-79 years) and the very elderly (age $\geq 80$ years). Our younger group showed better recanalization results compared to the older group $(86 \%$ vs. $60 \%$ ), and the major reperfusion rate (TICI $2 \mathrm{~B}-3$ ) was also 
significantly higher ( $75.3 \%$ vs. $40 \%$; $p=0.002)$ (Table 3$)$. Although there were different methods of treatment among these studies ${ }^{4,14)}$, these results suggest a likely poorer revascularization rate in the elderly compared to younger patients.

When failures after mechanical thrombectomy, including factors such as occlusion site, thrombectomy method and cause of failure was analyzed (Table 4), it was found that the cause of procedure failure was significant in the two subgroups. In the majority (92.3\%) of failed cases in patients aged 60-79, multiple approaches and attempts at recanalization were documented. However, in half (4 of 8) of the very elderly group, the occlusion site could not be accessed. Many studies reported age-related changes in the vasculature, including atherosclerosis of the vessel wall, media thickness, and hemodynamic modification ${ }^{1,9,15)}$. The mechanical thrombectomy was sometimes difficult due to a tortuous aortic arch or acute angulation of the proximal portion in old patients. Given a lack of research regarding these points in the cerebrovascular field, further investigation regarding age-related vascular changes and failed endovascular treatment is necessary.

Furthermore, when assessing thrombectomy results in the short term, poor outcomes (mRS 5-6) were identified in the very elderly, while good outcomes (mRS 0-2) were shown significantly more often in aged patients (Table 2). Chandra et al. ${ }^{4)}$ reported that an age of 80 years and over was a substantial predictor of poor outcomes at 90 days. Similarly, several studies ${ }^{6,12,18)}$ have shown a lower rate of good functional outcomes in patients aged 80 years and older for 3 months after intra-arterial or intravenous treatment. However, Pego et al. ${ }^{19)}$ pointed out that there was no significant difference in mRS score between older and younger patients who were treated with intravenous thrombolysis. This might suggest that age-related neuronal loss leads to decreased neurological reserve, which influences the poor functional recovery seen in very elderly patients at the time of discharge as well as at 3 months follow-up.

Table 3. Univariate logistic regressions of recanalization, clinical outcomes and complications

\begin{tabular}{|c|c|c|c|}
\hline & Patient & $\begin{array}{l}\text { Unadjusted } \\
\text { OR }(95 \% \mathrm{Cl})\end{array}$ & $p$-value \\
\hline \multicolumn{4}{|l|}{ Reperfusion (TICl) } \\
\hline \multicolumn{4}{|l|}{ Fail vs. partial+major } \\
\hline Age group ( $n=93$ ) & $13(14.0)$ & 1 & \\
\hline Very elderly group $(n=20)$ & $10(10.8)$ & $4.1(1.41-11.96)$ & 0.010 \\
\hline \multicolumn{4}{|l|}{ Major vs. fail+partial } \\
\hline Age group $(n=93)$ & $70(75.3)$ & 1 & \\
\hline Very elderly group $(n=20)$ & $8(40.0)$ & $0.22(0.08-0.60)$ & 0.003 \\
\hline \multicolumn{4}{|l|}{ Outcome (mRS) } \\
\hline \multicolumn{4}{|l|}{ Fair vs. good+poor } \\
\hline Age group ( $n=93$ ) & $37(39.8)$ & 1 & \\
\hline Very elderly group $(n=20)$ & $7(35.0)$ & $0.82(0.30-2.23)$ & 0.691 \\
\hline \multicolumn{4}{|l|}{ Poor vs. good+fair } \\
\hline Age group ( $n=93$ ) & $35(37.6)$ & 1 & \\
\hline Very elderly group $(n=20)$ & $13(65.0)$ & $3.08(1.12-8.45)$ & 0.029 \\
\hline \multicolumn{4}{|l|}{ Complication } \\
\hline \multicolumn{4}{|l|}{ Hemorrhage vs. none } \\
\hline Age group (n=93) & $14(15.1)$ & 1 & \\
\hline Very elderly group $(n=20)$ & $1(5.0)$ & $0.30(0.04-2.40)$ & 0.255 \\
\hline \multicolumn{4}{|l|}{ Progression vs. none } \\
\hline Age group (n=93) & $2(2.2)$ & 1 & \\
\hline Very elderly group $(n=20)$ & $3(15.0)$ & $8.03(1.25-51.72)$ & 0.028 \\
\hline \multicolumn{4}{|l|}{ Mortality vs. none } \\
\hline Age group $(n=93)$ & $16(17.2)$ & 1 & \\
\hline Very elderly group $(n=20)$ & $4(20.0)$ & $1.20(0.36-4.08)$ & 0.767 \\
\hline
\end{tabular}

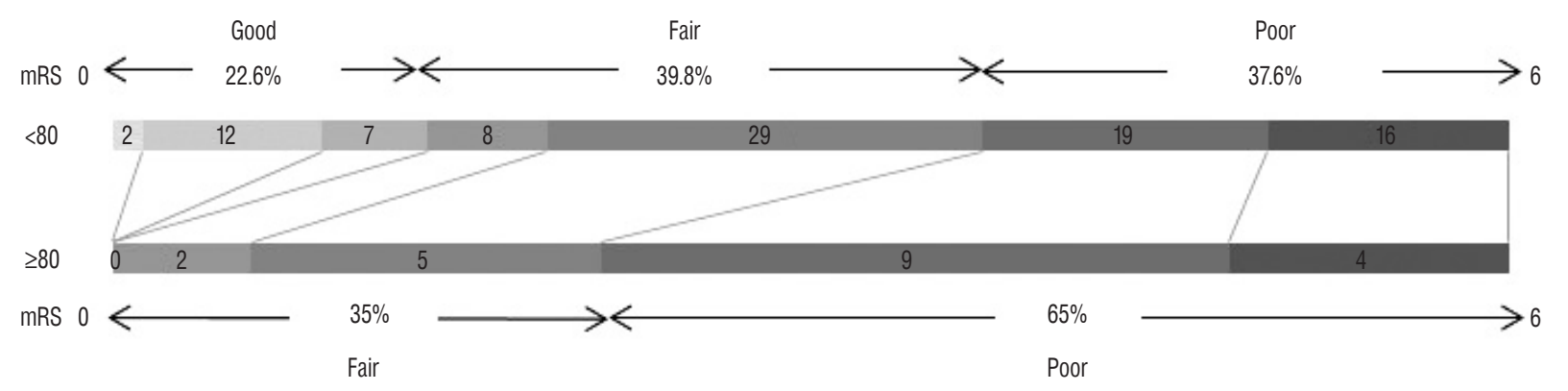

Fig. 1. Discharge modified Rankin Scale (mRS) score in very elderly patients (age $\geq 80$ years) and aged patient (60-79 years). 
Outcome of Mechanical Thrombectomy in Very Elderly Patients | Kim DH, et al.

Table 4. Analysis of the elderly patients who failed to mechanical thrombectomy

\begin{tabular}{|c|c|c|c|c|}
\hline & $\begin{array}{c}\text { Total } \\
(n=21)\end{array}$ & $\begin{array}{c}\text { Aged patient } \\
(60-79 \text { years }) \\
(n=13)\end{array}$ & $\begin{array}{c}\text { Very elderly patients } \\
\text { (age } \geq 80 \text { years) } \\
(n=8)\end{array}$ & $p$-value \\
\hline Age (years) & $74.7 \pm 8.2$ & $69.7 \pm 6.1$ & $82.8 \pm 2.7$ & $<0.001$ \\
\hline Male sex & $9(42.9)$ & $8(61.5)$ & $1(12.5)$ & 0.067 \\
\hline Location & & & & 0.368 \\
\hline $\mathrm{ICA}$ & $7(33.3)$ & $6(46.2)$ & $1(12.5)$ & \\
\hline MCA & $9(42.9)$ & $4(30.8)$ & $5(62.5)$ & \\
\hline $\mathrm{BA}$ & $4(19.0)$ & $2(15.4)$ & $2(25.0)$ & \\
\hline ACA & $1(4.8)$ & $1(7.7)$ & $0(0.0)$ & \\
\hline Treatment method & & & & 0.0867 \\
\hline Stent-retriever systems & $9(42.9)$ & $6(46.2)$ & $3(37.5)$ & \\
\hline Microwire maceration & $7(33.3)$ & $6(46.2)$ & $1(12.5)$ & \\
\hline None & $5(23.8)$ & $1(7.7)$ & $4(50.0)$ & \\
\hline Fail cause & & & & 0.0117 \\
\hline Unsuccessful procedure & $16(76.2)$ & $12(92.3)$ & $4(50.0)$ & \\
\hline Inaccessible lesion & $4(19.0)$ & $0(0.0)$ & $4(50.0)$ & \\
\hline Guiding failure & $1(4.8)$ & $1(7.7)$ & $0(0.0)$ & \\
\hline
\end{tabular}

Values are presented as mean \pm standard deviation or number (\%). ICA : internal carotid artery, MCA : middle cerebral artery, ACA : anterior cerebral artery, BA : basilar artery

Many studies have focused on the hemorrhagic transformation of complications after recanalization, and showed that these did not differ significantly in patients over 80 years compared with a younger group ${ }^{4,6,9,18,19)}$. In our study, there was no difference in hemorrhage, however infarction progression was observed eight times more frequently in very elderly patients (Table 3). Kim et al. ${ }^{13)}$ demonstrated that ischemia progression is the most common cause of early neurological deterioration after thrombolysis. It could be suggested that poor results from thrombectomy were manifested in the older age group due to greater infarction progression.

A limitation of this study is that patient data was collected and analyzed retrospectively in a single institution. In addition, the treatment methods and procedure indications for acute ischemic patients were somewhat heterogeneous, including different thrombectomy devices and various agents. In the early part of the study period, wire-based maceration was mainly used. However in the latter part of the study, the use of stent retrievers and balloon guiding catheters due to development of the devices appeared to improve the results of treatment. Finally, the evaluated outcome was discharge mRS, the follow-up period was variable, ranging from two days to several weeks, which could be too short to accurately assess the results.

\section{CONCLUSION}

There is little known from previous clinical trials regarding the established treatment for acute ischemic stroke in very elderly patients. Thus, it is necessary to consider the outcomes of various treatments in this group. Although mortality and other complications were similar to those of younger patients, patients over 80 years of age undergoing mechanical thrombectomy for acute infarction were more difficult to recanalize due to inaccessible occlusion sites and a higher rate of infarction progression. Therefore, the procedure recommended should be decided with prudence.

\section{References}

1. Auerbach $\mathrm{O}$, Hammond EC, Garfinkel L : Thickening of walls of arterioles and small arteries in relation to age and smoking habits. N Engl J Med 
$278: 980-984,1968$

2. Berkhemer OA, Fransen PS, Beumer D, van den Berg LA, Lingsma HF, Yoo AJ, et al. : A randomized trial of intraarterial treatment for acute ischemic stroke. N Engl J Med 372 : 11-20, 2015

3. Campbell BC, Mitchell PJ, Kleinig TJ, Dewey HM, Churilov L, Yassi N, et al. : Endovascular therapy for ischemic stroke with perfusion-imaging selection. N Engl J Med 372 : 1009-1018, 2015

4. Chandra RV, Leslie-Mazwi TM, Oh DC, Chaudhry ZA, Mehta BP, Rost NS, et al. : Elderly patients are at higher risk for poor outcomes after intra-arterial therapy. Stroke 43 : 2356-2361, 2012

5. Fonarow GC, Reeves MJ, Zhao X, Olson DM, Smith EE, Saver JL, et al. : Age-related differences in characteristics, performance measures, treatment trends, and outcomes in patients with ischemic stroke. Circulation $121: 879-891,2010$

6. Ford GA, Ahmed N, Azevedo E, Grond M, Larrue V, Lindsberg PJ, et al. : Intravenous alteplase for stroke in those older than 80 years old. Stroke 41 : 2568-2574, 2010

7. Goyal M, Demchuk AM, Menon BK, Eesa M, Rempel JL, Thornton J, et al. : Randomized assessment of rapid endovascular treatment of ischemic stroke. N Engl J Med 372 : 1019-1030, 2015

8. Goyal M, Menon BK, van Zwam WH, Dippel DW, Mitchell PJ, Demchuk $A M$, et al. : Endovascular thrombectomy after large-vessel ischaemic stroke: a meta-analysis of individual patient data from five randomised trials. Lancet 387 : 1723-1731, 2016

9. Hajdu MA, Heistad DD, Siems JE, Baumbach GL : Effects of aging on mechanics and composition of cerebral arterioles in rats. Circ Res 66 : 1747-1754, 1990

10. Hong KS, Ko SB, Yu KH, Jung C, Park SQ, Kim BM, et al. : Update of the Korean clinical practice guidelines for endovascular recanalization therapy in patients with acute ischemic stroke. J Stroke 18 : 102-113, 2016

11. Jovin TG, Chamorro A, Cobo E, de Miquel MA, Molina CA, Rovira A, et al. : Thrombectomy within 8 hours after symptom onset in ischemic stroke. N Engl J Med 372 : 2296-2306, 2015

12. Kim D, Ford GA, Kidwell CS, Starkman S, Vinuela F, Duckwiler GR, et al. : Intra-arterial thrombolysis for acute stroke in patients 80 and older: a comparison of results in patients younger than 80 years. AJNR Am J Neuroradiol 28 : 159-163, 2007

13. Kim JM, Moon J, Ahn SW, Shin HW, Jung KH, Park KY : The etiologies of early neurological deterioration after thrombolysis and risk factors of ischemia progression. J Stroke Cerebrovasc Dis 25 : 383-388, 2016
14. Loh Y, Kim D, Shi ZS, Tateshima S, Vespa PM, Gonzalez NR, et al. : Higher rates of mortality but not morbidity follow intracranial mechanical thrombectomy in the elderly. AJNR Am J Neuroradiol 31 : 1181 1185,2010

15. Lund-Johansen $P$ : The hemodynamics of the aging cardiovascular system. J Cardiovasc Pharmacol 12 Suppl 8 : S20-S32, 1988

16. Mazighi M, Labreuche J, Meseguer E, Serfaty JM, Laissy JP, Lavallée PC, et al. : Impact of a combined intravenous/intra-arterial approach in octogenarians. Cerebrovasc Dis 31 : 559-565, 2011

17. Mione $G$, Ducrocq $X$, Thilly N, Lacour JC, Vespignani $H$, Richard S : Outcome of intravenous recombinant tissue plasminogen activator for acute ischemic stroke in patients aged over 80 years. Geriatr Gerontol Int $16: 843-849,2016$

18. Mono ML, Romagna L, Jung S, Arnold M, Galimanis A, Fischer U, et al. Intra-arterial thrombolysis for acute ischemic stroke in octogenarians. Cerebrovasc Dis 33 : 116-122, 2012

19. Pego PM, Nunes AP, Ferreira P, Sousa C, Amaral-Silva A : Thrombolysis in patients aged over 80 years is equally effective and safe. J Stroke Cerebrovasc Dis 25 : 1532-1538, 2016

20. Powers WJ, Derdeyn CP, Biller J, Coffey CS, Hoh BL, Jauch EC, et al. : 2015 American Heart Association/American Stroke Association focused update of the 2013 guidelines for the early management of patients with acute ischemic stroke regarding endovascular treatment: a guideline for healthcare professionals from the American Heart Association/American Stroke Association. Stroke 46 : 3020-3035, 2015

21. Saver JL, Goyal M, Bonafe A, Diener HC, Levy El, Pereira VM, et al. : Stent-retriever thrombectomy after intravenous t-PA vs. t-PA alone in stroke. N Engl J Med 372 : 2285-2295, 2015

22. Tanne D, Gorman MJ, Bates VE, Kasner SE, Scott P, Verro P, et al. : Intravenous tissue plasminogen activator for acute ischemic stroke in patients aged 80 years and older : the tPA stroke survey experience. Stroke $31: 370-375,2000$

23. The Statistics Korea : Annual report on the cause of death statistics. Available from : http://kostat.go.kr/portal/korea/kor_nw/2/1/index. board? bmode $=$ read $\&$ bSeq $=\& a S e q=348539 \&$ pageNo $=2 \&$ rowNum $=10$ \&navCount=10\&currPg=\&sTarget=title\&sTxt=\%EC\% $82 \% A C \% E B \% A 7$ $\% 9 \mathrm{D}$

24. The Statistics Korea : Population and housing census. Available from : http://kosis.kr/statHtml/statHtml.do?orgld=101\&tbIld=DT_1IN0001_ ENG\&conn_path= 